\title{
From ancient Greek medicine to $\mathrm{EP}^{3} \mathrm{OS}$
}

\author{
E.P. Prokopakis ${ }^{1}$, P.W. Hellings ${ }^{2}$, G.A. Velegrakis ${ }^{1}$, H. Kawauchi ${ }^{3}$ \\ 1 Department of Otorhinolaryngology, University of Crete School of Medicine, Heraklion, Crete, Greece \\ 2 Department of Otorhinolaryngology, University Hospitals Leuven, Catholic University of Leuven, Leuven, \\ Belgium \\ 3 Department of Otorhinolaryngology, University of Shimane School of Medicine, Matsue, Shimane, Japan
}

\begin{abstract}
SUMMARY
The manuscripts of eminent Byzantine physicians from the 4th to the 14th century contain extensive information on various otorhinolaryngological issues. In their work, the early knowledge of rhinological disease from definition and symptoms to conservative treatment and surgical intervention is intriguing. Most of this meticulous knowledge was developed through time, beginning mainly from Hippocrates and the Hellenistic period. Thereafter, medicine developed through Roman and Byzantium times to finally influence European medicine and later the rest of the Western world. History of medicine reflects the history of mankind itself, and otorhinolaryngology follows closely this path. Our goal is to slim down and illuminate the most challenging of the vast amount of information on rhinological issues contained in the original Greek text of Hippocrates, and mainly in the hagiographical texts of Byzantine medical writers. In particular, we focus on rhinological diseases from antiquity till the time being, following the journey of evolution of topical and nebulizer therapy for sinonasal inflammatory diseases in Greece, from "milothris" to modern nasal sprays, leading to an understanding of the philosophy of our predecessors and the roots of modern rhinology.
\end{abstract}

Key words: $E P^{3} \mathrm{OS}$, rhinosinusitis, ancient medicine

\section{GENERAL ANCIENT MEDICINE CHARACTERISTICS}

In the history of mankind, human beings in any point of evolution invented apparatus and techniques for the treatment of disease and war-induced traumas. In the lower spheres of society, the above constitute what today could be referred to as traditional medicine. This kind of medicine corresponds to an evolutional level where sorcery, science and religion have not yet been clearly separated. The progress in the creation of solid social structures and relations slowly leads to a tendency of distinguishing science from this primitive framework. Medicine as a scientific system appeared initially as a 'Mediterranean phenomenon'.

The Mediterranean regions, shared by Indo-Europeans, Semites and Hamites, were an area of both hostile and peaceful encounters, hence engendering elements of variety and unity. This area shared a common basis of technological and navigational skills. Furthermore, the cultural sharing and interface around the Mediterranean basin is nowhere else more specifically and clearly demonstrated than in the development of medicine in antiquity, leading to what one could call, 'the Mediterranean sea of knowledge' ${ }^{(1)}$.

It appears that Egyptian civilization was the first - in this area of the world - to report an important progress regarding the practice of medicine, since none or limited established data exist from the period before. As quoted in the texts of Herodotus, who is well known as the father of history, "Medicine has been divided by them (the Egyptians) according to categories. Each physician is a specialist in one illness and in no more..." The first known doctor is Sekhetinanch, who lived approximately 3500 years B.C. during the reign of Pharaoh Sahura. In papyrus dated back to those times, it is mentioned that the doctor managed to cure 'the kings' nose'. In other similar manuscripts, more than 50 surgical techniques of reconstruction of nasal injuries and fractures are documented, presenting methods that are not far away from the ones used till today in simple nasal traumas.

Egyptian medicine involved an empirical therapeutic system, which aimed in one point or another at finding a non religious pathogenetic explanation. The basic principles of ancient Greek medicine include significant Egyptian elements. Traces of Egyptian medical theories can be found in the work of Hippocrates, leading to the unforced assumption that Egyptian medicine has influenced Greek medicine in a continuous and unbreakable line of scientific evolution. Furthermore, Egyptian surgical practice accumulated a body of material, along with pharmacological data, that were in one way or another absorbed into their Greek counterparts ${ }^{(2)}$. 


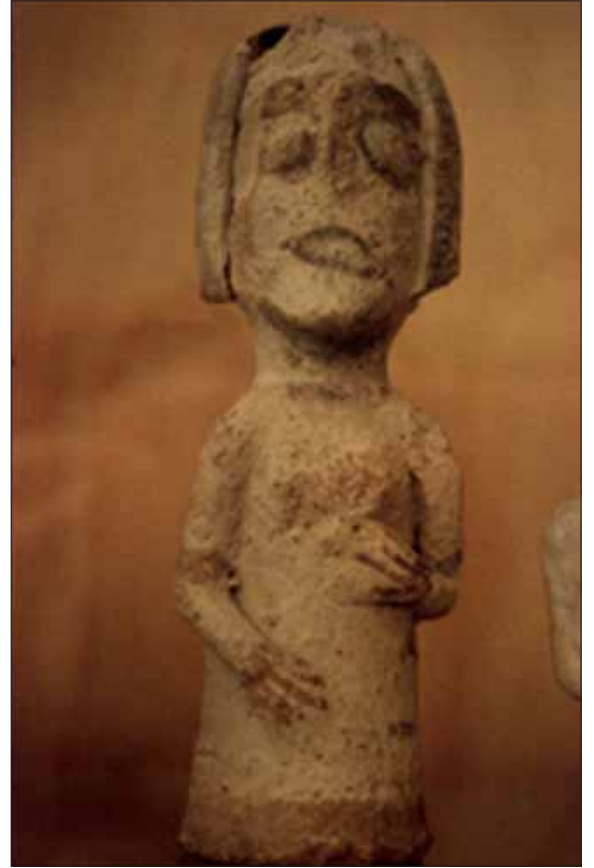

Figure 1. Paralysis of the facial nerve (Crete, 2500-2000 B.C.).

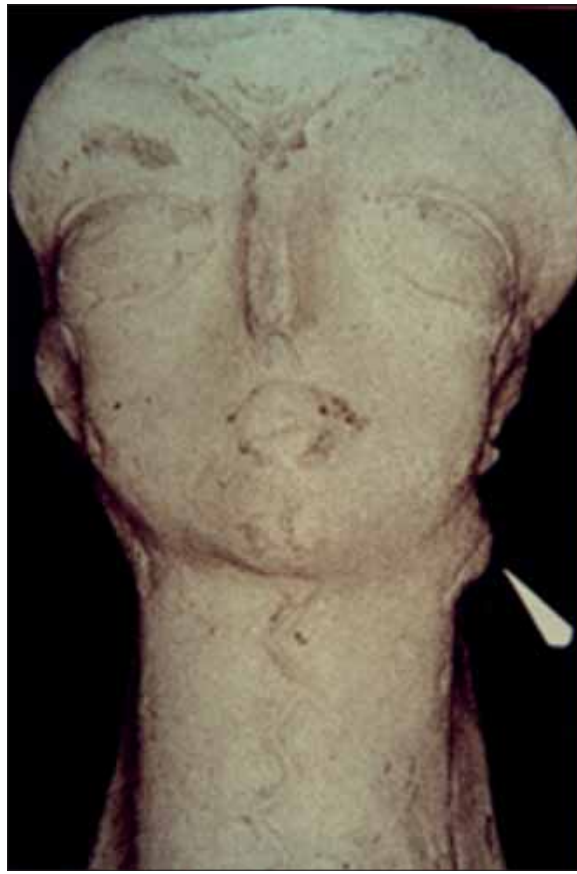

Figure 2. Neck mass (Crete, 1400 B.C.).

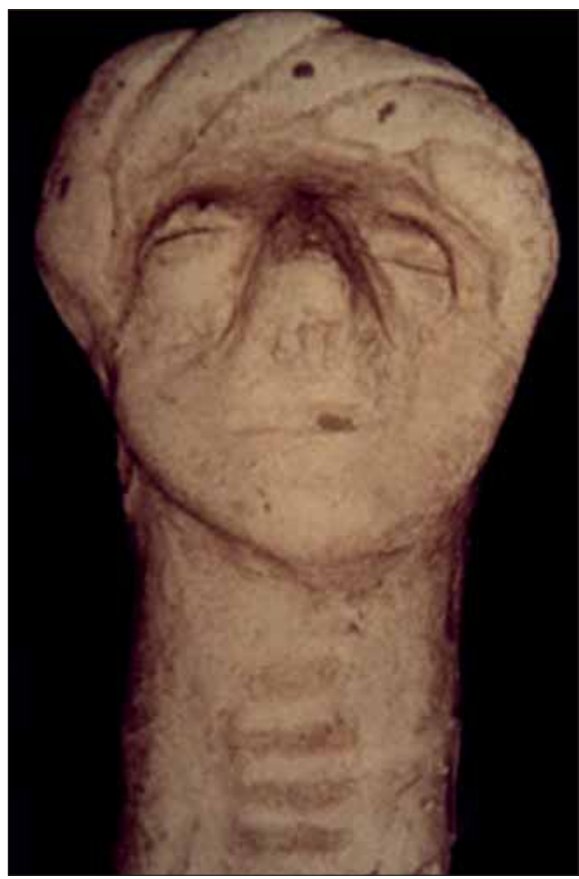

Figure 3. The larynx and the trachea (Crete, 1400 B.C.).
In parallel with Egyptian civilization, Crete depicts an exponential growth. The 300 years that preceded 1450 B.C. mark the zenith of the Minoan civilization, which is known as the first civilization in Europe. Minoan medicine is mainly revealed from studying frescoes, idols, sculptures, instruments and various written documents. In these idols, various otorhinolaryngological pathologies are revealed, indicating the Minoan knowledge of this region. All of these findings are at display in the permanent collection of the National Archaeological Museum of Heraklion, Crete (Figures 1, 2, and 3).

Therefore Greek medicine had already begun from the $6^{\text {th }}$ century to form the shape of a defined science, since it had in many points antedated Egyptian medicine. The first major breakthroughs in medicine are documented back to the $6^{\text {th }}$ century B.C. in the first Greek treatise 'About nature' ("Peri physeos"), written by Alkmaion of Kroton, in which he reported his research on the neurosensory organs ${ }^{(3)}$. Greek medicine, as a fully organized and coherent scientific system with detailed and developed branches of anatomy, physiology, clinical description, nutrition and treatment, appears for the first time in the methods of the ancient medical schools of Knidos and Kos. Euryfon, who is regarded as the traditional founder of the medical school of Knidos, applicated a medical thinking similar to that of the first Egyptian physicians, only to be soon overwhelmed by the teachings of the medical school of Kos, which present the blastocytes of modern Western medicine. It is in the face of Hippocrates, 'the father of medicine' and his work, that ancient Greek medicine emerged as a secular science disburdened from sorcery, religious beliefs and prejudices. 'The Hippocratic Corpus' during the late $5^{\text {th }}$ and the early $4^{\text {th }}$ century
- a sizeable body of treatises - besides its abundance of anatomical, physiological, pathological and therapeutic details, consists the first ever medical document based only on clinical observation. Hippocrates suggests for the first time the concept of "totality" and the key point of medicine being the understanding of the human body. In his studies "Prognostikon", he points out the role of 'prognosis' as the most important factor for the prevention, the diagnosis, the progress, as well as the treatment of illness. Moreover, he believed that in any step of medicine and treatment, including rhinology, the understanding of anatomy and physiology is essential, since it provides the doctor the ability to distinguish the differences between what is normal and what is abnormal ${ }^{(4)}$.

\section{RHINOLOGICAL KNOWLEDGE IN HIPPOCRATIC ERA}

In Hippocrates' study "About polyps and their removal", there is knowledge of the communication between the nasal cavity and the pharynx since there is a description of patients' cases where liquids came out from the nose due to swallowing disability. Hippocrates also describes the respiratory track and characteristically the trachea as the organ that starts from the pharynx, ends in the lungs and is composed of rings connecting breathing to the nose. He suggests the necessity of examining both nasal cavities in cases of breathing disturbances as this may occur due to obstruction in one of them ${ }^{(5)}$.

As Hippocrates believed, head catarrh resulted from an insulted nose being bulged and filled with egesta (secretions). In another source describing a case of rhinitis due to frontal sinusitis and its treatment, we find the knowledge of the communication between the sinuses and the nasal cavity. "... This can also happen due to topical causes as a damaged tooth..." 
he adds, further addressing the issue of acute and chronic sinusitis ${ }^{(5)}$.

Hippocrates attempted to understand the nasal physiology by explaining the consistence of reflexes during sneezing. Underlining the significant role of sneezing in the treatment of frontal sinusitis, he proposed that in some cases it has to be provoked to achieve better results in removing secretions. Hippocrates was especially concerned about the nasal cavities' clearance so that "they must remain open since any kind of abnormality may cause many disturbances". He suggests the curative properties of vinegar and honey solution as an expectorant that benefits breathing by clearing the nose and the trachea from egesta, which produce hoarseness. Another solution proposed having similar properties is Ptisani (barley flour). However, he doesn't neglect to point out the risk of possible side effects as, “.... doctor should be very careful since it can cause death if the secretions go down to the lungs when the patient is too weak to cough and discharge them..." ${ }^{(5)}$ Ptisani is again referred in an advertisement in 1872 (see box) ${ }^{(6)}$.

“Guyot's Tar replaces ptisani in the treatment of colds, bronchitis, coughs, and catarrhs. Guyot's Tar is employed with the greatest success in the following diseases: - As a Draught - A teaspoonful in a glass of water, or two tablespoonfuls in a bottle : Bronchitis, Catarrh of the Bladder, Colds, Obstinate Coughs, Irritation of the Chest, Hooping, Cough, Diseases of the Throat, Pulmonary Consumption. As a Lotion. - Pure or diluted with a little water: Affections of the Skin, Itchings, Diseases of the Scalp. Guyot's Tar has been tried with the greatest success in the principal hospitals of France, Belgium, and Spain. Experience has proved it to be the most hygienic drink in hot weather and in time of epidemics. Detailed instructions accompany each bottle. General depot in Paris: L. Fjuke, 19, Rue Jacob."

\section{NASAL POLYPS AND HIPPOCRATES}

Polyps were one of the most favorite topics for Hippocrates, as it appears in some books of the "Corpus Hippocraticum", as well as to others Hippocratic physicians ${ }^{(7)}$. The writer of the work "Diseases II" (perhaps Dracos or Thessalus, sons of Hippocrates), devotes an extensive analysis on polyps. He remarks that "a polyp forms in the nose and hangs down from the central cartilage like an uvula, having a soft consistency and moving during breathing in and out of the nostril, thus effecting the voice and causing snoring" (8).

Table 1. Polyps classification according to Hippocrates.
1. Mobile polyps with a "mischus"
2. Immobile polyps
3. Polyps protruding like "round meat"
4. Polyps tough like a stone
5. Polyps like cancer

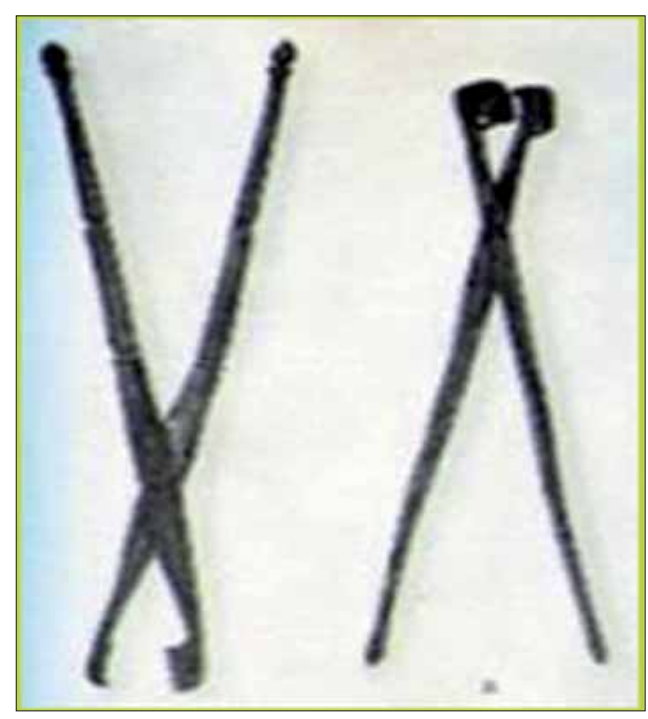

Figure 4. Instruments used in the removal of nasal polyps.

Hippocrates himself separated nasal polyps into five different categories: mobile polyps with mischus (the Greek word for flower stalks), immobile polyps, polyps protruding like "round meat", polyps tough like a stone and finally polyps like cancer (Table 1). For the treatment of polyps, he started with conservative treatment and then, in cases of failure, proceeded to the use of various surgical methods, with many different instruments - such as suction tubes, rhinoscopes, cautery instruments, inhalation devices like today's nebulizers, and syringes, which seem to be the first nasal sprays in the history of medicine $^{(9)}$ (Figure 4).

Among non-invasive procedures, he describes a method to introduce hot steam produced from a cauldron of boiling water or vinegar, which is covered air-tight with only an extended pipe that reaches the patients' nose, and another method of puffing into the nose air containing finely ground therapeutical herbs through a straw. These methods were passed on to Roman and Byzantine medical practice in the centuries to follow ${ }^{(10)}$.

One of his surgical interventions was cauterization of the polyp with an iron probe and a rhinoscope that protected the walls of the nasal cavity from burning. After repeating the cauterization three to four times, a special black powder called "elleoborus" from a herbaceous perennial plant, Helleborus foetidus, native to Western Europe - was applied and finished with the use of a tampon of antiseptic drugs and sea water (Figure 5).

The "sponge" and the "loop" techniques were initially used by Hippocrates for the removal of nasal polyps. These methods can be considered as surgical interventions or manipulations, and continued to be used in Europe until at least the $19^{\text {th }}$ century. In the "sponge" technique, a sponge like a small ball with size relative to the opening of the nostrils - is made and is wound with a cord of Egyptian linen so that it is hard. Then the sponge is bound with threads in four places and the threads are passed through the loop end of a tin flexible 


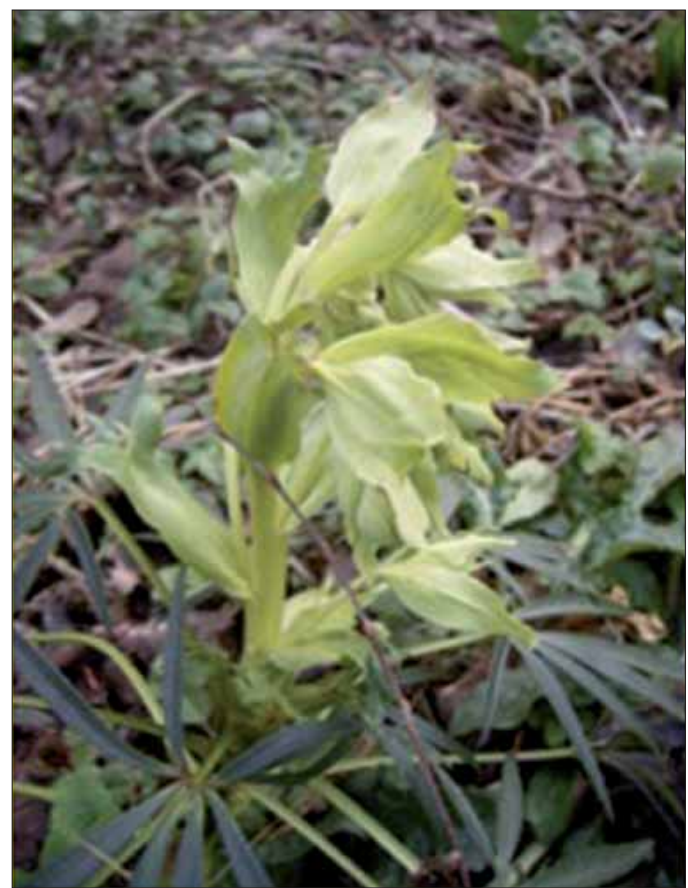

Figure 5. Helleborus foetidus.

curette. The other end of the curette is inserted into the nose until it reaches the mouth and is drawn out. Finally, the physician removes the polyps by pulling the threads with the help of a guide placed under the uvula as a support (Figure 6). The second method, the "loop", is similar and is used mainly in polyps that are spherical and soft, projecting into the nasal cavity. A small noose is made, adjusted and stretched over the polyps, and again with the assistance of a special probe placed under the uvula, the physician removes the polyps by pulling the cord through the mouth (Figure 7).

"Milothris" was an instrument created for repeatedly clearing the nasal cavity by Byzantine physicians, based on the mentioned Hippocratic techniques. It consisted of a piece of sheep wool impregnated with several substances - such as chyle of cypress apples, roots of the herb dracontion, a caustic solution of quicklime, copper, niter and alum dissolved in lime waterand oil, which was introduced deep into the nose with the aid of a suture that passed from the nose to the mouth and was then cleared with palindromic movements ${ }^{(11)}$ (Figure 8).

\section{BYZANTINE RHINOLOGY}

In Byzantium, the political, cultural and scientific center of the Western world from $324 \mathrm{AC}$ until $1453 \mathrm{AD}$, talented physicians paid considerable attention to diseases of the nose, the pharynx, the larynx and the ear ${ }^{(12)}$. Their contribution to the history and even more to the development of Otorhinolaryngology is substantial, since they preserved important pharmaceutical treatments and surgical operations of celebrated ancient Greek physicians ${ }^{(13)}$. The work of Oribasius ( $4^{\text {th }}$ century), Alexander of Tralles ( $6^{\text {th }}$ century), Aetius of Amida ( $6^{\text {th }}$ century), Paul of Aegina ( $7^{\text {th }}$ century), Leon the iatrosorhist $\left(9^{\text {th }}\right.$ century), Theophanes Chryssovalantes ( $10^{\text {th }}$ century), Michael Psellus ( $11^{\text {th }}$ century), Nicolaus Myrepsus ( $13^{\text {th }}$ century), and Ioannes Actuarius ( $14^{\text {th }}$ century), contain extended chapters with descriptions of the treatment of rhinitis, ozena and nasal malodour, ulcers, anosmia, polyps, epistaxis, bruises, fractures and cancer ${ }^{(14)}$. Some of these physicians have described specific surgical techniques for various nasal diseases, and especially for the removal of polyps and reconstruction of the nose in cases of defects and fractures ${ }^{(15)}$. Most of them, especially those in the early period between the $4^{\text {th }}$ and the $7^{\text {th }}$ century, were trained in the famous Medical School of Alexandria, following Hippocratic, Hellenistic and Roman medical traditions and complying accounts from the relevant texts, thus enriching medical science with their wealth of experience ${ }^{(13-15)}$.

During the Byzantine period, not only did the medical tradition of Hellenic and Roman antiquity survive, but there were new contributions to medical thought and new practices and terms introduced. The use of herbal, animal and chemical substances - such as ammonium, scammony, castoreum, myrrh, Agaricus, Helleborus niger, bdellium and others - as the main basis for remedies is shown in medical texts dated back to this era ${ }^{(16)}$.

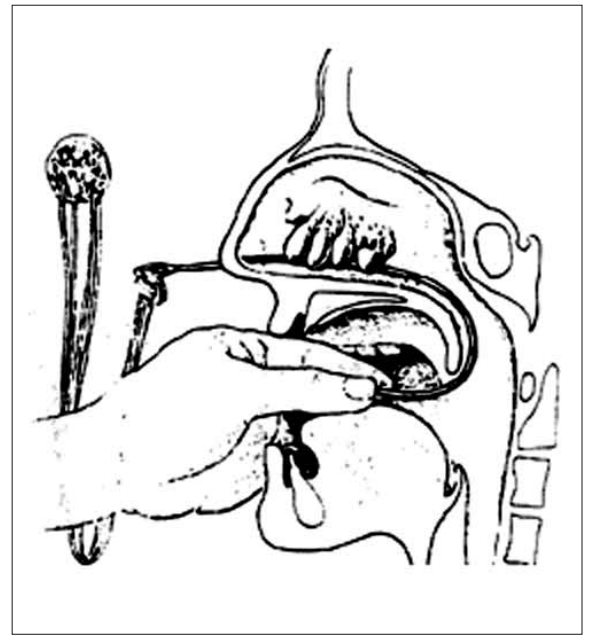

Figure 6. The "sponge" technique.

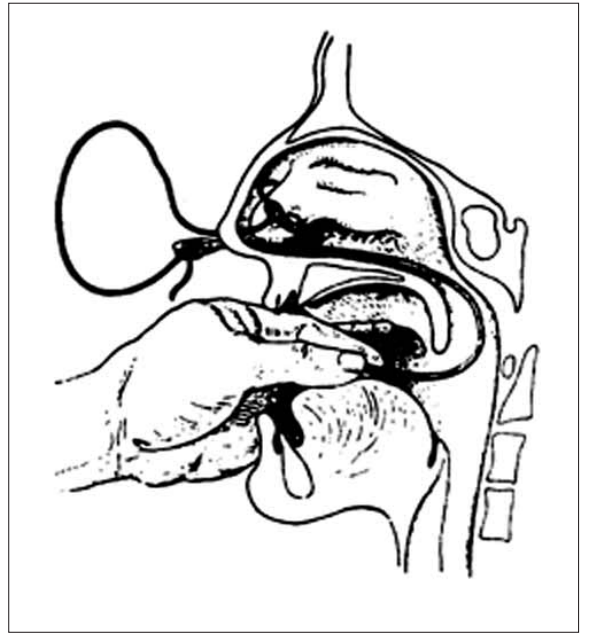

Figure 7. The "loop" technique.

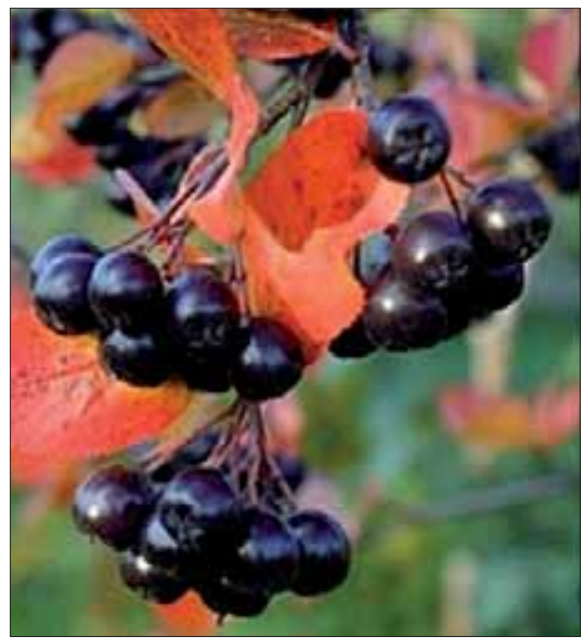

Figure 8. Dracontiun. 
Myrepsos, a famous physician and pharmacologist from the $13^{\text {th }}$ century A.D., used in nasal cancer a mixture of egg shells, burned nut flakes and burned palm tree bark ${ }^{(17)}$. Earlier in the $6^{\text {th }}$ century A.D., Aetios of Amida had suggested another wellknown medicine of his time, "drakontion" - an herb for snake bites. In nasal odour caused by polyps, Byzantine physicians dropped a powder consisting of kissos, myrrh and dried roses into the nose. For dyspnea, caused by nasal blockage, they used "Xirion of Theodore", consisting of grapes, myrrh and dried roses ${ }^{(18)}$.

In cases of epistaxis, Byzantine medicine suggested plugging the nose with gauze or spraying pharmaceutical substances to stop the bleeding. Alexander and Aetios suggested a specially made burned sponge soaked with oil. The first applied plane tree root while the second applied a paste of "hypouris", a plant growing near water, and Sith recommended cinnamon ${ }^{(19)}$.

Nasal polyposis seems to have occupied the medical thought of Byzantine times from very early, since an effort to explain the cause of the disease and apply the appropriate treatment is recorded in medical texts of that period. Aetius, while attempting a definition, reports that "They resemble the color and composition of the sea creature with the same name and are caused by thick and gluey humors descending from the head". Paul of Aegina in his work "About polyps" suggested that a polyp is "A tumor which is created in the nose and takes its name from the marine animal because it resembles the flesh of the creature and its behaviour; as the animal protects itself with its tentacles, so do polyps react and extend in the nose of the sufferer, obstructing the nostrils and provoking dysfunction in breathing and talking". Ioannes Actuarius described the mass as "A hypersarcoma, which obstructs the ethmoid openings of the nose and often spreads to nearby openings of the nose, and prevents inhaling and exhaling, as well as secretion flow" (20).

The first to use several substances in an effort to conservatively treat nasal polyps was Oribasius, in the $4^{\text {th }}$ century A.D.

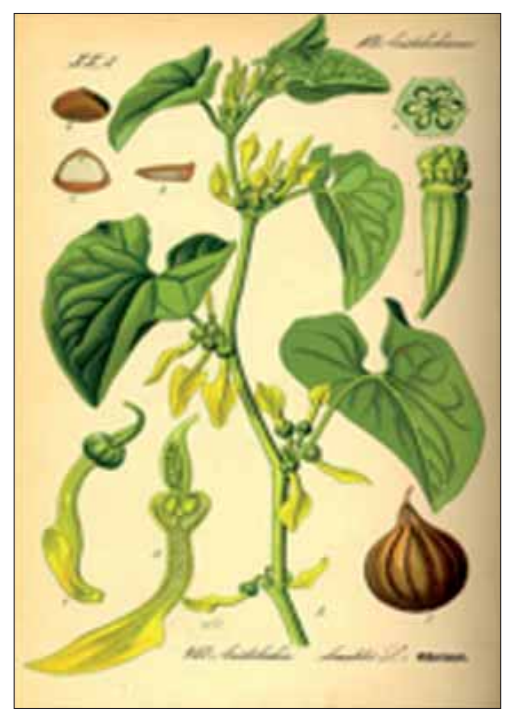

Figure 9. Aristolochia Clematitis.

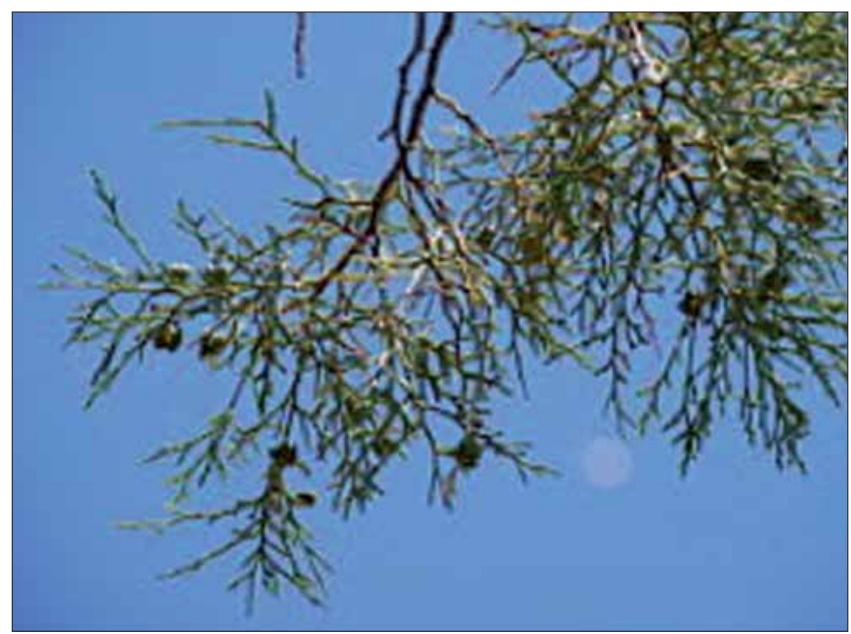

Figure 10. Tetraclinis Articulata.

He applied a mixture composed of grated myrrh, incense, egg white and snails, to the head for nine days as systematic treatment, and then local-nasal treatment followed. He recommended inunctions using a feather to apply caustic substances that will slowly devour polyps. The mixture described is one consisting of chyle of apples of cypress, roots of the herb dracontium, or a caustic solution of quicklime, copper, niter and alum dissolved in lime water, as suggested in the cleaning of the nasal cavity with the use of "milothris", a few centuries ago. He also proposed the blowing of various substances such as flowers of copper, alum, iron, myrrh, incense and the herb Aristolochia - into the nose with the use of a straw (Figure 9). Furthermore, he used a chyle of chopped pomegranate that has been boiled in a tin container so that it is solid enough to be kneaded into small particles that will be inserted into the nose. Finally, if the polyps are deeper towards the nasopharynx, Oribasius recommended inunctions of several dry drugs on the palate with feathers or the use of "milothris" (21).

Aetius of Amida believed that the proper treatment of nasal polyps should be first etiologically and then locally. He suggested the drying out of the head with the use of poultices and inunctions, especially on the temporal area, after having completely shaved the head for better application. Afterwards he followed the steps of Aetius, using a powder that consists of alum, myrrh, sandarach, copper and the herb Tetraclinis Articulata inserted into the nose with a probe, after cleansing the nostrils with an infusion of aromatic wine (Figure 10). Another technique is blowing with a straw, while the patient keeps his or her mouth full of water, of a powder of flowers of copper dissolved in strong vinegar and left out to dry in the sun on a very hot day. The aim of these methods is based clearly on the belief that these substances can dissolve the polyps mass, leading to the cure of the disease. In cases of persistent polyps, Aetius suggested even stronger caustics, such as mustard seed, that is pounded in water and then forms small 
grained pieces, again applied into the nose with the use of a different kind of "milothris" - with only one end left outside the nose - and this time left in the nasal cavity and removed after 1 day. He also conveyed to us a series of local treatments for nasal polyps taken from the ancient physicians Apollonius $\left(1^{\text {st }}\right.$ century B.C.), Aslepiades from Bithynia ( $1^{\text {st }}$ century B.C.), and Antipater and Galen ( $2^{\text {nd }}$ century A.D.). Aetius meticulous directions reached the point of even suggesting a special drug that contained dry rose petals "for eunuchs who have a softertextured body and are considered to be more sensitive". Finally, he confessed that he added in a drug administered to a rich patient with polyps, an old aromatic wine, since the patient had requested it ${ }^{(22)}$

The contemporary anatomic belief was that excretions from the brain, passing through small pores of the meninx-that was believed to be attached directly to the ethmoids- reached the nostrils. Therefore, an attempt to dry these excretions in their place of origin seemed at the time only to be reasonable. The conservative treatments of Oribasius and Aetius, aimed at devouring polyps by applicating caustic substances, are quoted from the works of Galen, who first used dracontion, pomegranate, copper and sandarach, blowing them into the nose with a straw or a probe wrapped in wool. However, besides copying this knowledge, it is obvious that Byzantine physicians added new information and personal observations ${ }^{(23)}$. Other Byzantine physicians later on followed the same methods. Theophanes Cryssovalantes accepted the etiological approach of the whole body purgation and suggested conservative treatments similar to those of Aetius with blowing or inunctions. Myrepsos also followed the prescriptions of Aetius, applying caustic powders locally, while a small number of others such as Leon the Iatrosophist recommended only surgical methods ${ }^{(24)}$.

\section{MODERN TIME SOLUTIONS AND EVOLUTION TO EPOS}

There was no major contribution to medical practise during the Ottoman Empire in Eastern Mediterranean countries, with the exception of Nicolas Taptas, who specialized in diseases of the nose, throat and ear, and is considered to have introduced endonasal dacryocystorhinostomy instead of the external approach, for the treatment of dacryocystits ${ }^{(25)}$. Byzantine medicine proved to be the leading medical school in Western Europe until centuries to follow.

The medical practice of the $19^{\text {th }}$ and early $20^{\text {th }}$ century was based mainly on French and German medical schools. Even though knowledge of the possible pathogenic factors of nasal disease start to differ from the medical data that had survived through time since antiquity, nasal irrigations are still used for treating common rhinological issues. The common belief is that irritation of the nasal mucus in the middle meatus causes oedema and provokes the formation of polyps. Therefore the application of substances into the nasal cavity to control
Table 2a, b, and c. Solutions for common cold.

a.

Eucalyptus oil ${ }^{(26)} \quad 5 \mathrm{gr}$

Benjoin ${ }^{(27)} \quad 10 \mathrm{gr}$

Alcohol $90^{\circ} \quad 90 \mathrm{gr}$

1 tea spoon in 1 lt boiling water

b.

Myrtle oil 4 gr

Baume of Peru ${ }^{(28)} 10 \mathrm{gr}$

Alcohol $90^{\circ} \quad 90 \mathrm{gr}$

1 tea spoon in 1 lt boiling water

c.

Sodium perborate monohydrate ${ }^{(29)}$

Sodium bicarbonate ${ }^{(30)}$

4-6 coffee spoons per 1 lt of water

Table 3a, b, c, and d. Solutions for acute rhinitis

a.

Acute rhinitis (prophylaxis)

Cocaine chlorhydrate ${ }^{(31)} \quad 0.2 \mathrm{gr}$

Resorcine oil $\quad 0.25 \mathrm{gr}$

Eucalyptus oil $0.1 \mathrm{gr}$

Vaseline $15 \mathrm{gr}$

b.

Acute rhinitis (treatment)

Eucalyptus oil $\quad 0.25 \mathrm{gr}$

Resorcine oil $0.25 \mathrm{gr}$

Vaseline $25 \mathrm{gr}$

c.

Acute rhinitis (treatment)

Eucalyptus oil $0.1 \mathrm{gr}$

Cocaine chlorhydrate $\quad 0.15 \mathrm{gr}$

Vaseline $15 \mathrm{gr}$

d.

Acute rhinitis (treatment)

Baum of Peru $0.5 \mathrm{gr}$

Vaseline $20 \mathrm{gr}$

inflammation and the mechanical removal of inflammatory secretions by irrigations was obligatory if one intended to cure the disease. A certain amount of liquid was applied into the nose, without pressure, through a small tube, in the form of todays' nasal drops.

The solutions used at the time were aiming to treat conditions such as common cold, acute and chronic rhinitis, acute sinusitis and ozaena and contained a great number of ingredients such as eucalyptus oil, baume of Peru, benjoin, resorcine oil, menthol, myrtle oil, geranium oil, thyme oil, camphora, boric acid, vaseline and cocaine - well known for their therapeutical effect - in various proportions, as presented in Tables 2-6 ${ }^{(26-35)}$. As illustrated above, the substances are totally different from those used in nasal irrigations up to then, but surprisingly remain the same with the ones used in todays' medicine, as proven in a common internet search using the terms "common cold, flu, rhinitis, symptom relief" as key words. 
Table 4a, b, c, and d. Solutions for chronic rhinitis.

a.

Bicarbonete de soude $\quad 80 \mathrm{gr}$

Borate de soude $60 \mathrm{gr}$

Chlorure de sodium $\quad 50 \mathrm{gr}$

Thyme oil ${ }^{(32)} \quad 1 \mathrm{gr}$

1 lt of boiling water

b.

Eucalyptus oil or camphor $\quad 15 \mathrm{gr}$

Boric acid 4 gr

Vaseline $20 \mathrm{gr}$

c.

Resorcine oil $0.3 \mathrm{gr}$

Huile sterilisee $15 \mathrm{gr}$

d.

Monosulfure de sodium $5 \mathrm{gr}$

Glycerin $25 \mathrm{gr}$

Eau distillee $75 \mathrm{gr}$

Table 5. Solution for acute sinusitis.

\begin{tabular}{lr} 
Menthol $^{(33)}$ & $4 \mathrm{gr}$ \\
Alcohol $90^{\circ}$ & $100 \mathrm{gr}$ \\
$1 \mathrm{~L}$ boiling water & \\
\hline
\end{tabular}

Table 6. Solution for Ozaena.

\begin{tabular}{lc} 
Vaseline & $60 \mathrm{gr}$ \\
Boric acid & $20 \mathrm{gr}$ \\
Geranium oil ${ }^{(34)}$ & $2 \mathrm{drops}$ \\
Sodium perborate & $100 \mathrm{gr}$ \\
2 coffee spoons per 1L water & \\
\hline
\end{tabular}

Nowadays, various nasal irrigation solutions are available, since different "home recipes" exist. Manufactured powders or solutions can be bought over the counter, the tonicity of which varies with the use of isotonic to hypertonic saline. Additives can be included so that the $\mathrm{pH}$ can be altered and numerous devices can be used for administration. The exact mechanism of the way nasal irrigations work remains undetermined even today. Some of the most accepted existing theories suggest various routes such as clearing mucus, affecting ciliary's beat frequency and therefore affecting mucocilliary clearance. As even the pathogenesis of rhinosinusitis is often enigmatic inflammatory versus infectious, bacterial versus virus - only adds to the dilemma.

In the departments of Otolaryngology, at the University Hospital of Crete, as well as in Shimane University Hospital and the University Hospital of Leuven, the guidelines are fully described to the patients, since without some planning, the use of nasal irrigations can be rather awkward and messy (Table 7). When nasal irrigations are used frequently, simplicity is far better than a complex, theoretically superior procedure. The chosen solutions should not be too cold or too hot and irrigations can be performed over a kitchen sink, over the bathroom basin, or, indeed, in the shower. The shower provides a ready source of non sterile water at a chosen temperature thus helping in the appropriate administration. In performing positivepressure nasal irrigations, producing a " $\mathrm{K}$ " sound as the patient administers the solution may be beneficial. This elevates the soft palate and helps to reduce the somewhat uncomfortable problem of nasal irrigations from being transmitted to the oropharynx.

According to the $\mathrm{EP}^{3} \mathrm{OS}$ guidelines for the management of rhinosinusitis, therapies such as antral washings, mycolytic agents, and phytomedical preparations even though having very little evidence of efficacy are in common use in certain groups of patients and clinicians ${ }^{(36)}$. Nasal douching is, however, recommended in adults with chronic rhinosinusitis. Saline nose drops or sprays are especially popular among paediatricians in acute rhinosinusitis, since isotonic saline at body temperature can reduce oedema and nasal secretions ${ }^{(36)}$.

\section{PAST, PRESENT AND FUTURE}

There are very few nations worldwide - such as Japan, India, China, Egypt, and Greece - able to claim that their medical background and contribution to patient's care counts back millenniums. The evolution of medicine in Greece, from ancient times till today is synonymous to European flair, since Western world medicine origins from Hippocratic principles ${ }^{(37)}$. Moreover, German, French, Dutch, Latin and British medical traditions that are considered as the leading schools in

Table 7. Different nasal irrigations.

\begin{tabular}{|c|c|c|c|c|}
\hline Nasal irrigations & Liquid & Salt & Baking soda & Final Tonicity \\
\hline Brown et al. & $\begin{array}{l}4 \mathrm{cc}(1 \mathrm{qt}) \text { of water, boiled } \\
\text { for } 5 \mathrm{~min}\end{array}$ & $11 / 2$ level tsp of table salt & None & $0.9 \%$ \\
\hline Talbot et al. & $\begin{array}{l}1 \text { qt glass jar, filled with } \\
\text { bottled water }\end{array}$ & $\begin{array}{l}2-3 \text { heaping tsp of pickling } \\
\text { or canned salt }\end{array}$ & 1 rounded tsp & $3 \%$ \\
\hline Rabago et al. & $1 \mathrm{pt}$ of tap water & $\begin{array}{l}1 \text { heaping tsp of canning } \\
\text { salt }\end{array}$ & $1 / 2 \mathrm{tsp}$ & $2 \%$ \\
\hline ENT CLINIC University of Crete & $250 \mathrm{ml}$ of water & $1 / 2$ tsp of table salt & $1 / 3 \mathrm{tsp}$ & $1.2 \%$ \\
\hline
\end{tabular}


Europe refer and accept their Greek influence and contribution. This influence dominated European medicine until the medieval era. Since the expansion of interest in studies on the pathophysiology and treatment of rhinosinusitis in Europe during the last two decades, a novel state of the art document on rhinosinusitis was baptized with the greek word $\mathrm{EP}^{3} \mathrm{OS}$, which is a lengthy narrative poem, ordinarily concerning a serious subject containing details of heroic deeds and events significant to a culture or nation ${ }^{(38)}$. $\mathrm{EP}^{3} \mathrm{OS}$ stands for the "European Position Paper on Rhinsinusitis and Nasal Polyps", and provides an overview of current knowledge on epidemiology, pathophysiology, diagnostic procedures and treatment options for rhinosinusitis. In contrast to previous centuries, evidence-based medicine was the guidance for critical analysis of recommended treatment strategies. As a virtue of the $\mathrm{EP}^{3} \mathrm{OS}$ document, evidence-based treatment algorithms are provided to ENT doctors, as well as for patients affected with common cold, acute and chronic rhinosinusitis. The journey through time gives us the opportunity to learn how our specialty evolved in some of the most exciting periods of human history by brilliant men who tried to understand human nature. Thus, it is extremely interesting to thoroughly scope the history of topical and nebulizer therapy for sinonasal inflammatory diseases in Greece, allowing physicians dealing with the nose, not only to address the similarities and differences between Western and Eastern medicine through centuries, but also to underline the importance of the steps made so far.

\section{REFERENCES}

1. Helidonis E. Current Otorhinolaryngology. Chapters xv-xvi. Athens: Pashalides, 2002.

2. Heinrich von Staden. Herophilus: The Art of Medicine in Early Alexandria. Pages 1-26. Cambridge University Press, 1989.

3. Jones W. H. S. Philosophy and Medicine in Ancient Greece. Baltimore: Johns Hopkins Press, 1946.

4. Edelstein L. Hippocratic prognosis, in Ancient Medicine. Pages 6585. Baltimore: Johns Hopkins University Press, 1967.

5. Lloyd G. E. R., ed. Hippocratic writings. London: Penguin Books Ltd., 1983.

6. Daily Southern Cross, Volume XXVIII, Issue 4526, page 4, 27 February 1872.

7. Wright J. A history of laryngology and rhinology. Chapter 55, p 9293. Philadelphia, Pa: Lea and Febiger, 1914.

8. Purnaropoulos G, Emmanuel C. Hippocrates. All his works. Vol 4. Pages 198-201. Athens, Greece: Martinos, 1971.

9. Pottter P. Hippocrates. Vol 5. Pages 246-253. Cambridge, Mass: Harvard University Press, 1998.

10. Puschmann T. Alexander von Tralles. Chapter II. Pages 79-145. Amsterdam: Band. A.M. Hakkert, 1963.

11. Den Ven Van P. La Vie Ancienne de S. Symeon Stylite le Jeune. Vol I. Pages 41-218. Bruxelles: Societe des Bollandistes, 1962.

12. Troianos S. Sorcery and medicine in Byzantium. Chapter 9. Pages 309-327. Themes Obstet Gynaecol, 1995.

13. Lascaratos J. Otorhinolaryngological diseases in Byzantium: information from non-medical literary sources. J Laryngol Otol 1996; 110: 913-917.
14. Lascaratos J, Assimakopoulos D. Surgery on the larynx and pharynx in Byzantium: early scientific description of these operations. Otolaryngol Head Neck 2000; 122: 579-583.

15. Lascaratos J, Cohen M, Voros D. Plastic surgery of the face in Byzantium in the fourth century. Plast Reconstr Surg 1998; 102: 1274-1280.

16. Ramoutsaki I, Papadakis C, Ramoutsakis I, et al. Therapeutic methods used for otolaryngological problems during the Byzantine period. Ann Otol Laryngol 2002; 111: 553-557.

17. Myrepsus N. About composition of the drugs. Code 1478. National Library of Athens, f. 137.

18. Eutychiadis A. Introduction to the Byzantine therapeutics. Athens, Greece: Parisianos, 1983.

19. Duffy J. Byzantine medicine in the sixth and seventh centuries: aspects of teaching and practise. Chapter 38. Pages 21-27. Baltimore: Dumbarton Oak Papers, 1983.

20. Lascaratos J, Segas J, Assimakopoulos D. Treatment of nasal polyposis in Byzantine times. Ann Otol Laryngol, 2000; 109: 871-876.

21. Milne JS. Surgical instruments in Greek and Roman times. Pages 39-94. London: Clarendon Press, 1907.

22. Olivieri A. Aetii Amideni libri medicinales. Chapters V-VIII. Pages 234-242 Berlin: B. Teubner, 1950.

23. Raeder I. Oribasii collectionum medicarum reliqviae. Vol 3. Pages 16-17. Leipzig and Berlin: B. Teubner, 1931.

24. Ermerins FZ. Anecdota medica Graeca. Pages 152-153. Amsterdam: A. Hakkert, 1963.

25. Lascaratos G., Trompoukis C., Segas J, et al. (1871-1955): A pioneer of post-laryngectomy voice rehabilitation. The Laryngoscope, 2003; 113: 702-705

26. Escat E. Technique Oto-Rhino-Laryngologique. Paris : A. Maloine et Fils, 1921.

27. http://en.wikipedia.org/wiki/Eucalyptus_oil

28. http://fr.wikipedia.org/wiki/Benjoin

29. http://www.aromatherapybible.com/baume_de_perou.php

30. 39. http://en.wikipedia.org/wiki/Sodium_perborate

31. $31 \mathrm{http}: / /$ en.wikipedia.org/wiki/Baking_soda

32. http://en.wikipedia.org/wiki/Resorcinol

33. http://en.wikipedia.org/wiki/Thyme

34. http://en.wikipedia.org/wiki/Menthol

35. http://en.wikipedia.org/wiki/Pelargonium

36. Fokkens W, Lund V, Mullol J. European position paper on rhinosinusitis and nasal polyps 2007. Rhinol Suppl. 2007: 1-136.

37. Helidonis E., Prokopakis E. The contribution of Hippocratic oath in third milleniun medical practise. Am J Otolaryngol 2001; 22: 303-305.

38. http://en.wikipedia.org/wiki/Epic_poetry

Emmanuel P. Prokopakis, MD, Ph.D

Department of Otorhinolaryngology

University of Crete School of Medicine

University Hospital of Crete

A' Building $3^{\text {rd }}$ Floor

University Ave.

71110 Heraklion

Crete

Greece

Tel: +30-69-3223 7622

E mail: emmanuel@prokopakis.gr 